
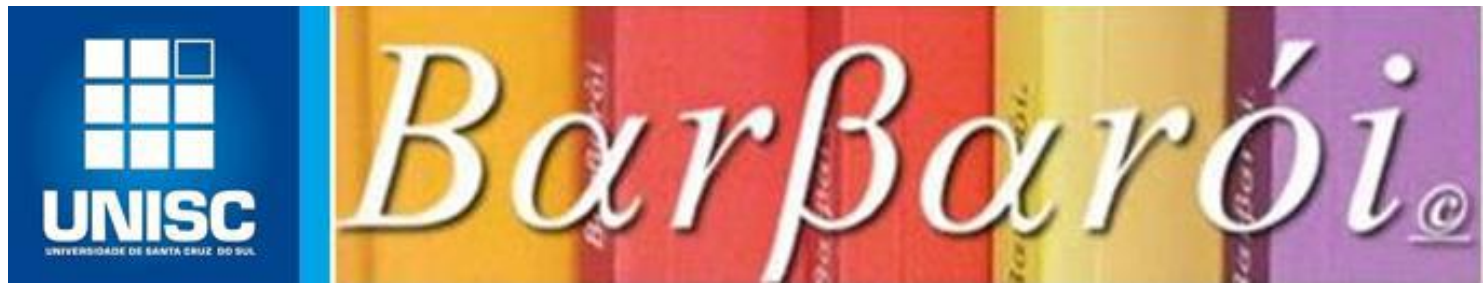

\title{
LAÇOS COM A LOUCURA: A CIDADE COMO ESPAÇO DE PROMOÇÃO DE SAÚDE MENTAL
}

DOI: http://dx.doi.org/10.17058/barbaroi.v1i53.11828

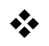 \\ Luísa Susin dos Santos \\ Universidade Federal do Rio Grande do Sul - UFRGS-Brasil \\ Camila Klein \\ Universidade Federal de Santa Catarina - UFSC - Brasil \\ Ana Lucia Mandelli de Marsillac \\ Universidade Federal de Santa Catarina - UFSC-Brasil \\ Ariane Kuhnen \\ Universidade Federal de Santa Catarina - UFSC - Brasil

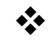

\section{Resumo}

Este ensaio aborda a relação da cidade com a loucura. Busca analisar o espaço público com suas normas e desvios e refletir sobre o cuidado em saúde mental. Aborda o dispositivo do Acompanhamento Terapêutico em sua perspectiva antimanicomial e de fortalecimento do cuidado em liberdade. Dialoga com a perspectiva da psicologia ambiental e da psicanálise para refletir sobre essa complexa trama entre loucura, cidade, laço social e saúde mental.

Palavras-chave: Acompanhamento terapêutico; Psicanálise; Psicologia Ambiental.

\section{Introdução}

“[...] se a loucura não é nem um déficit, nem uma dissociação de funções, então ela tem muito a nos ensinar; ela lança luz sobre aquilo que está presente no dito normal e, desse modo, concerne a todos". (JULIEN, 1999, p.7)

Nas cidades, estão inscritas as memórias e identidade do habitante e de seus grupos sociais. É nela também onde se tecem as relações entre os sujeitos considerados "loucos" e o território onde circulam. Refletir sobre a loucura e suas relações com a cidade implica em analisar a relatividade entre o que vem a ser a normalidade e a loucura, em determinado tempo e 
espaço. Desse encontro conceitual, torna-se possível vislumbrar estratégias de promoção de saúde, ancoradas no fortalecimento do laço social.

Neste texto, buscamos uma interlocução sobre o tema da loucura nos tempos e espaços da cidade e suas relações com a saúde mental. . O método é eminentemente analítico e envolveu a escolha da temática, bem como a necessidade de fortalecer subsídios teóricos para as práticas de promoção de saúde mental nas cidades. O encontro conceitual entre a Psicologia Ambiental (PA) e a Psicanálise revelou-se fundamental para refletir sobre essa complexa temática e subsidiar práticas nessa via ${ }^{1}$. Ao longo do ensaio, analisa-se, primeiramente, o que vem a ser a norma e a loucura nos laços sociais e nas cidades. Articula-se a essa discussão a perspectiva antimanicomial, que, no campo da saúde mental, orienta o cuidado pela valorização da singularidade dos sujeitos e em liberdade. Nesse sentido, o dispositivo do Acompanhamento Terapêutico (AT), foi destacado como uma clínica do sujeito na cidade; revelando-se como uma importante estratégia de promoção de saúde mental, na medida em que propõe o fortalecimento dos laços entre os habitantes nas cidades, instigando redes afetivas e de cuidado.

A PA ocupa-se das inter relações entre pessoa e ambiente, levando em consideração, sobretudo, os atributos físicos deste último, sejam eles naturais ou construídos. Parte-se da premissa que a relação pessoa-ambiente é de reciprocidade, na medida em que um afeta o outro, ou seja, o sujeito constrói-se a partir de sua experiência com uma realidade sócio-física ao passo que também é produtor desta realidade. Logo, tal compreensão considera a bidirecionalidade da interação, de forma que os aspectos psicológicos são analisados face à sua implicação com o ambiente (GÜNTHER; ROZESTRATEN, 2005; PINHEIRO, 2003).

O AT é uma modalidade clínica destinada aos casos que envolvem maior risco psicossocial, seja pelo isolamento ou pela exclusão que alguns sujeitos se encontram, por diferirem e interrogarem a normalidade social. O AT vai ao encontro do sujeito, podendo ser realizado na casa, na rua, nas praças ou nas instituições onde o acompanhado se encontre ou tenha interesse em estar. Quando pautado na ética e método da psicanálise, ganha contornos singulares, focando sua prática no sujeito acompanhado, nos seus desejos e possibilidades. Entende-se que essa escuta e intervenção tenham efeitos sobre o sujeito, mas também sobre o laço social, na medida em que incide e amplia o espaço de circulação daqueles que diferem e que tradicionalmente são excluídos. Nesse sentido, interroga as normas de inclusão e busca minimizar 
as vulnerabilidades que se agravam pelo cerceamento da circulação desses sujeitos (PALOMBINI 2004; 2007; 2009; HERMANN, 2013).

O presente artigo intenta discutir como promover saúde mental e ao mesmo tempo enfrentar os processos históricos de exclusão da loucura na cidade em suas dimensões espacial, política e ética. A partir do entrelaçamento teórico entre PA e psicanálise, pensa-se em um sujeito que se constitui no laço social e na relação com os espaços e lugares na cidade, logo, debate-se aqui, o direito à cidade, o cuidado em liberdade e o acolhimento à diferença, visando enfrentar e diminuir situações de exclusão e iniqüidades.

\section{O Espaço Público}

A cidade constitui-se na realidade imediata, no dado prático-sensível, e impõe-se no plano arquitetônico, enquanto o "urbano" revela-se por meio das realidades sociais, das relações construídas pelas subjetividades: cidade e vida urbana, que proclamam a indissociabilidade entre o plano concreto e as relações sociais. As aglomerações urbanas transformam-se à medida que mudam as sociedades, e tal transformação encontra-se no caminho intermediário entre mudanças amplas, relacionadas à economia, ao Estado, aos poderes políticos, e aquilo que é da ordem imediata - as relações diretas entre pessoas e grupos sociais. Lefebvre (2011), para compreender a cidade como o meio termo entre a vida cotidiana e as instâncias de poder, chama de ordem próxima as relações dos indivíduos em grupos razoavelmente organizados e mais ou menos amplos, e de ordem distante aquilo que se situa em um nível "superior" formado pelo Estado, a Igreja, as instituições jurídicas, a cultura e as ideologias.

A ordem distante projeta-se na realidade prática (ordem próxima), revelando-se nas relações de produção e de propriedade, inscrevendo-se nos espaços e nas vidas comuns. Ela traça, recorta e define o desenho da cidade - mas também é tensionada por este plano da vida imediata. Para além de sua dimensão tangível, a cidade é produto e produtora de sujeitos e possui "[...] uma história; ela é uma obra de uma história, isto é, de pessoas e de grupos bem determinados que realizam essa obra nas condições históricas” (LEFEBVRE, 2001, p. 52).

Logo, há um investimento histórico na constituição das cidades que contribuiu para a decadência da vida coletiva. Propositado ou não, o fato é que a moderna configuração do tecido urbano resultou na dissolução da própria urbanidade - que pressupõe a vida na cidade como o exercício da alteridade, bem como do confronto de diferenças de múltiplas ordens, sejam elas 
sociais, econômicas, político-ideológicas e de modos de viver (LEFEBVRE, 2001) Para entender este fenômeno de deterioração ou abandono dos núcleos urbanos, é mister olhar para trás e acompanhar o percurso histórico das cidades que, lentamente, afastaram-se do ideal de coletividade para se tornarem espaços da estranheza.

Revisitando a ágora grega e o fórum romano, depara-se com espaços públicos para onde afluíam cidadãos, escravos, prostitutas, mercadores, políticos e religiosos - sítios da diversidade, auto-exposição e contato entre as pessoas (SENNET, 2008). Adiantando alguns séculos, chega-se aos núcleos das antigas cidades medievais, que congregavam o comércio, a religião, a política, a produção de bens e a produção intelectual (LEFEBVRE, 2001). Tais espaços constituíam-se cenários fervilhantes da vida em sociedade na Antiguidade e na Idade Média e opunham-se a rusticidade da vida no campo: a cidade dava lugar às ideias.

Com a revolução sanitária das cidades promovida pelo avanço das ciências médicas, em meados de 1740, a administração de grandes centros europeus passou a cuidar da limpeza urbana, por meio da implantação de sistemas de esgoto, da regulamentação da conservação dos passeios públicos e da limpeza das áreas defronte às residências. Nesta época, a analogia de que a cidade é como um corpo, cujas artérias e veias deveriam permitir a livre circulação de pessoas, toma força entre os administradores públicos. O tecido urbano passa a incorporar em seu desenho avenidas, ruas de mão única e grandes intersecções, e inaugura uma nova forma de locomoção, que até hoje perdura: a do indivíduo sozinho, impelido ao movimento acelerado, sujeito às demandas do tráfego. As exigências da circulação eficiente resultam em corpos dessensibilizados, que não se conectam com o espaço onde circulam: nas cidades emergem espaços neutros, áreas urbanas reservadas para os indivíduos em locomoção e não mais para multidões em movimento (SENNET, 2008).

Além da modificação das ruas e avenidas, os espaços públicos, outrora ocupados pela feira, pelos grupos em protesto e pelas festas religiosas, também ganham nova configuração após a revolução francesa. Se a prioridade era facilitar a circulação das multidões e desencorajar os movimentos de grupos organizados, era necessário criar grandes espaços abertos, cuja amplitude permitiria a fácil vigilância dos habitantes da cidade.

Chega-se às cidades planejadas do século XIX, cujos espaços públicos de convívio e pausa são afetados por esta nova ordem, que os desvaloriza por meio da priorização da locomoção e que promove o arrefecimento do sentimento de partilha e da cidade como bem 
comum (SENNET, 2008). Além das modificações arquitetônicas, a retirada das moradias dos pobres dos centros urbanos, reforça o que Lefebvre (2001) chama de destruição da urbanidade, já que procura padronizar - dentro de um ideal burguês de cidadão - os corpos que circulam no centro da cidade: é a negação da diversidade constituinte da essência das cidades.

A partir do século XX, os discursos pacificadores suprimiram o espaço conflitivo da cidade, bem como o senso de coletividade, a abertura aos dissensos e a possibilidade de diferentes expressões. Além disso, contribuíram para a restrição dos espaços de convívio, negociação e sociabilidade; negando as diferenças e diminuindo a possibilidade de compartilhar o mundo em que se vive, em prol da globalização e do sucesso econômico (PALOMBINI, 2007; ROUDINESCO, 2000). Frente ao medo da desordem e à valorização da competitividade eminentemente material, “o silêncio passa então a ser preferível à linguagem, fonte de angústia e vergonha" (ROUDINESCO, 2000, p. 30).

\section{Tempos e Espaços da Norma e da Loucura}

Na perspectiva da psicanálise, desenvolvida nas obras de Freud (2010/1930) e Lacan (1992), o termo laço social remete às relações com os outros, atravessadas pela cultura e civilização. Pode-se dizer que o laço é aquilo que tenta amenizar a condição de desamparo própria da condição humana, criando relações entre os sujeitos, entre estes e o espaço social, bem como suas redes afetivas e de cuidado. Os rituais, os ideais, os valores estão articulados, na busca de amparo simbólico e imaginário, paradoxalmente também são fonte de mal-estar, na medida em que os sujeitos não se coadunem a eles. Freud (2010) sustenta que as situações traumáticas, como perdas, desastres, separações, precariedade extrema, reavivam o estado de desamparo primordial, o qual é inerente à própria condição humana, que precisa de um outro para sobreviver. Esse desamparo é protótipo para as situações traumáticas geradoras de angústia no adulto, que ao confrontá-lo, remetem à condição primária estrutural de incompletude. Cabe ressaltar que é justamente essa condição humana de desamparo que possibilita a constituição do laço social, da organização do espaço e da própria subjetividade, que se estrutura nessa relação.

O desamparo e as vulnerabilidades são conceitos importantes para pensarmos a relação da subjetividade com o laço social e com o espaço. As vulnerabilidades são diversas, resultantes de ameaças que vêm de diferentes direções; já o desamparo é um conceito metapsicológico 
psicanalítico que remete a uma experiência fundamental da condição humana e é em torno dela que se constitui a posição do sujeito no laço social (BETTS, 2014).

$\mathrm{Na}$ contemporaneidade, na medida em que se acompanha a degradação de espaços comuns, cujos entrelaçamentos marcam as diferenças subjetivas e do laço social, é notório o movimento de reclusão dos sujeitos, resguardando-se entre os muros de suas casas em busca de apaziguamento, isolamento e individualização. Vive-se em tempos em que reina a era da individualidade, evidenciando a primazia do indivíduo, caracterizada pela ilusão da liberdade irrestrita e de uma historicidade sem história (ROUDINESCO, 2000). Cabe ressaltar que, neste emaranhado, o individual diverge da ordem do singular, enquanto que o primeiro está atrelado a uma não-historicidade e uma independência das relações, o segundo evidencia a fundamental relação com o outro e, também, com a história. No modelo econômico, capitalista e neoliberal, no qual todos são vistos como capazes de adquirir e acessar, a lógica hegemônica sustenta uma ideia de indivíduo, que, supostamente, poderia ser destacado de sua historicidade e contexto social. Como consequência desse modelo, é possível observar que tudo aquilo que destoa desses ideais retorna ao indivíduo e não ao laço social, esfacelando com isso uma perspectiva de coletividade.

A contemporaneidade carrega o peso do enfraquecimento do sentido da vida, pela sobreposição das razões de mercado, criando uma ilusão de satisfação do desejo, pela aquisição de bens materiais, acentuando uma perspectiva de subjetividade reduzida a imagens (ROUDINESCO, 2000). Sustentando-se na primazia da visão e da imagem, identifica-se uma sociedade comandada pelo olhar. Esta análise pode ser encontrada tanto na perspectiva da sociedade do espetáculo proposta por Guy Debord, quanto pela sociedade disciplinar descrita por Michel Foucault. No encontro entre o ser visto e o controle de si, o psicanalista Antonio Quinet (2002) caracteriza e conceitua a sociedade contemporânea como escópica. Neste cenário, tem-se a conjugação do existir implicado a um ser visto pelo Outro $^{2}$ e, ao mesmo tempo, ser vigiado a todo o momento pelo Outro, através de atos e pensamentos, como a figura do Grande Irmão da literatura de George Orwell e o Panóptico de Bentham (BETTS, 2007).

Jaime Betts (2007), ao retornar a Quinet (2002), ressalta o quanto as aparências ocupam o centro do palco na sociedade escópica. Para além de um ideal de ser a partir do ter, um indivíduo é reconhecido como tal em meio à multidão, a partir do momento em que é visto: ele precisa além de ter, parecer e aparecer. Diante desse cenário, não é de se admirar que a supremacia da imagem 
leve aqueles que desviam do ideal contemporâneo ocidental e capitalista à estigmatização, exclusão, punição e eliminação, de maneira violenta, silenciosa e trágica.

Vive-se, então, em meio à lógica de produção e consumo, permeada pela competitividade e eficiência, categorizando os que são úteis e adequados ao sistema, sendo considerados assim como normais. Ao mesmo tempo, é notória a marginalização daqueles que não compartilham com os ideais dominantes: os considerados loucos, moradores de rua, drogadictos, pessoas com deficência e imigrantes. Aqueles que vivem na contramão de seu tempo acompanham o agravamento de sua solidão pelo desprestígio social da tristeza e da diferença. Kehl (2009) entende o aumento contemporâneo das depressões como sintoma de um tempo, reiterando que ocupam, na contemporaneidade, um lugar de sinalizador do "mal-estar na civilização". A depressão é um sintoma social dominante no nosso tempo, já que, lenta e silenciosamente, desfaz a teia de sentidos e de crenças que sustenta e ordena a vida social do nosso tempo.

A experiência do tempo na contemporaneidade pauta-se sobretudo na velocidade, tal como o bem conhecido jargão: "Tempo é dinheiro!". As depressões da atualidade, mas também os quadros de sofrimento psíquico grave, tais como as psicoses, drogadição, pânico ou mesmo o autismo, estão intimamente relacionados à experiência de um tempo lento, que está na contramão da lógica dominante da nossa época. São sujeitos que sofrem por um sentimento de tempo estagnado, desajustado do tempo do mundo do capital, incapacitados de sintonizar com a urgência do tempo contemporâneo (KEHL, 2009).

De todos aqueles que permanecem, muitas vezes, no confinamento dos manicômios ou até mesmo do próprio lar, restritos aos serviços de saúde e assistência social, circulando ou permanecendo nas margens das cidades, interessa neste artigo focar nas possibilidades de inserção no espaço social daqueles considerados psicóticos. A psicose é o sinônimo por excelência, em nosso tempo, da loucura e da alienação. Os sujeitos acometidos por ela apresentam, muitas vezes, produções delirantes e forma de organização distinta dos ideais de seu tempo. Eles partem de outras perspectivas de tempo e espaço, confrontando o que se entenderia como normal, pois não se adequam ao "pacto" social do bem viver.

A teoria psicanalítica auxilia na reflexão sobre essa estruturação subjetiva e seus efeitos no laço social. Contardo Calligaris (1989) esclarece que na neurose (que poderia ser considerada a normalidade, no nosso laço social contemporâneo) o sujeito organiza-se a partir da função paterna, que faz corte na relação dual do bebê com a mãe, sendo exercida pelo próprio pai, pelo 
trabalho ou por algum outro que exerça a função de terceiro nessa relação primordial. A função paterna indica ideais a serem seguidos, em sintonia com o laço social, supondo que esses ideais defendam o sujeito e o protejam do mal-estar e do desamparo inerentes ao viver. Seja em conformidade ou oposição a esses ideais, o neurótico baliza sua subjetividade e a percepção da realidade, a partir desses ideais dominantes. Assim, esse corte que a função paterna produz organiza toda a rede simbólica subjetiva, contribuindo para que o sujeito se organize no laço social. Já na estruturação psicótica, de outro modo, depara-se com a não inscrição desse terceiro organizador, pelos mais diversos motivos. A falta desta referência central produz a carência de um saber que oriente e distribua suas significações, fazendo com que a realidade psíquica se projete na realidade de forma massiva. Palombini (2004) ressalta que a ausência de um corte organizador que opere na estruturação psíquica afeta radicalmente a experiência subjetiva do espaço e do tempo na psicose.

Não havendo partilha dos traços simbólicos que organizam o laço social, o psicótico tende a ser excluído e a se isolar. Sua percepção de tempo é singular, o espaço parece invadir-lhe, as metas partilhadas não têm sentido. Por não crer em um saber compartilhado que o defenda do mal-estar, como fazem os chamados "normais", cria seu universo e segue as vozes e imagens que o habitam, sem as colocar em dúvida. O delírio, nesse sentido, é uma tentativa de amarração, de constituição de uma metáfora que o oriente e de obtenção de alguma significação; é, portanto, uma construção. O delírio carrega um valor de verdade para o sujeito, diz de uma posição subjetiva e assume uma via de escuta e tratamento na perspectiva da psicanálise. A produção delirante, dessa forma, não busca ser abolida ou confrontada, pois é justamente ela que permite ao psicótico produzir uma realidade menos insuportável, condizente com suas condições subjetivas (HERMANN, 2013).

O confinamento da dita loucura é pensado por Madeira (2014) como um ataque ao malestar da civilização, ao considerar a predominância do paradigma social da neurose e o fato da psicose expor à neurose alguma verdade que se quer esconder. Considerando que a crise psicótica é um inconsciente a céu aberto que expõe os conteúdos recalcados na neurose, Madeira (2014) supõe que o confinamento evoca essa condição estrutural da neurose de afastar o intratável. Para além disso, entende-se aqui que a loucura se sustenta como um funcionamento próprio, irredutível a outros e há de ser reconhecida como tal diante de sua condição estrutural (ELIA, 
2005); mas é imprescindível reiterar que ela é atravessada por questões políticas, históricas e sociais atrelada aos saberes e ao exercício de poder.

\section{A Luta Antimanicomial}

Aos que se sentem convocados e interrogados pela loucura, não é novidade que a obra de Michel Foucault intitulada A História da Loucura apresente uma contribuição fundamental para se pensar as práticas de confinamento e exclusão atreladas aos loucos. O autor ressalta que a loucura é herdeira da lepra no que concerne ao enclausuramento, sendo este baseado nas políticas de purificação urbana. Mesmo diante do desaparecimento da lepra e do apagamento da figura do leproso, as estruturas destinadas a suprimi-la e mantê-la distante, permanecem. E permanecem à espera de uma nova encarnação do mal, de um novo esgar do medo e de mágicas renovadas de purificação e exclusão social (FOUCAULT, 2010).

De maneira hegemônica, a lógica do confinamento do louco esteve atrelada ao hospital psiquiátrico, espaço institucional que carrega trajetórias históricas e hierárquicas. O hospital, com suas práticas cristalizadas e o isolamento do sujeito, é um exercício de dominação, no qual se neutraliza outros poderes que podem ser exercidos de fora e se contempla um poder terapêutico e

de adestramento. É o espaço que permite a descoberta da doença, ao mesmo tempo que assume um lugar de confronto, choque e disputa, onde se trata de vitória e submissão (FOUCAULT, 1979). Foucault (1979) recupera as análises de Basaglia (1985), afirmando que a característica de uma instituição como o hospital é a separação decidida entre aqueles que têm o poder e aqueles que não o têm.

O movimento da Luta antimanicomial e a Reforma Psiquiátrica configuram-se como um conjunto de estratégias de desospitalização, desinstitucionalização e anti medicalização, que não se reduzem a um modelo assistencial. Além da teórico-assistencial, as dimensões epistemológica, jurídico-política e sociocultural também clamam por transformações (AMARANTE, 2011). Nesse sentido, Birman (1992) ressalta que a Reforma Psiquiátrica não tem como objetivo a reformulação dos serviços, mas sim a transformação do lugar social da loucura; de como a sociedade lida com o dito louco, como ela constrói estigmas, leis e discriminações para lidar com este outro ameaçador, perigoso, assustador e estranho.

A atual conjuntura retrata a reprodução do modelo tradicional do hospital em lugares diferentes, numa dimensão de mero deslocamento, já que descentralizar o leito não provoca 
mudanças na escuta, na clínica, no diagnóstico e no trabalho com a família e com os sujeitos, trazendo a herança e contaminação do clássico modelo de tratamento (AMARANTE, 2011). Diante deste cenário, as quatro dimensões acima referidas: a escuta, a clínica, o diagnóstico e o trabalho, são fundamentais para uma concepção mais ampla do processo de Reforma, que não se restringe simplesmente a alteração dos espaços. Essas dimensões devem ser transversais ao sistema de saúde e necessitam atuar na desconstrução dos estigmas sociais do louco ameaçador e insensato (reforçados continuamente pelas instituições psiquiátricas). A clínica ampliada busca qualificar o tratamento ao usuário, familiares, mas também transformar o lugar social da loucura e o conceito de doença.

A concepção de doença mental que a Reforma visa transformar é aquela pregada pelo hospital, o lugar de eclosão da verdadeira doença, cujo papel não era apenas revelá-la, mas também produzi-la (FOUCAULT, 1979). Foucault faz alusão ao hospital psiquiátrico como um lugar de diagnóstico e classificação que se assemelha a uma horta, onde as espécies de doenças são divididas e cultivadas. O manicômio, além de ter suas práticas pautadas na tutela e custódia dos ditos incapazes, apresenta-se eminentemente focado na doença, deixando o sujeito e sua historicidade e subjetividade entre parênteses. Nesse sentido, cabe reiterar que a instituição em questão na Reforma é a loucura, e não propriamente o manicômio.

A noção de instituição inventada, proposta por Rotelli (1990), sustenta-se na perspectiva da invenção de espaços institucionais que promovam o cuidado, mas não a clausura. A instituição inventada confronta tanto a denominada instituição afirmada (na via da instituição total, que toma conta do usuário e não permite qualquer circulação no espaço social), quanto a instituição negada (na via de uma recusa às instituições, em uma suposição de que o cuidado em saúde mental possa prescindir desta). Enquanto a instituição afirmada aproxima-se da lógica do manicômio e da produção da doença mental, a instituição negada parte de uma concepção de que a loucura não existe, negando suas particularidades (ROTELLI, 1990). Nesse sentido, caberia, segundo o autor, inventarmos instituições que permitam o cuidado em liberdade.

Em 2001, no Brasil, institui-se a Lei: 10.216, que versa sobre "os direitos e a proteção das pessoas acometidas de transtornos mentais". Com ela vários direitos foram alcançados, ainda que a efetivação de muitos deles esteja distante. Hoje em dia, pode-se analisar que as políticas derivadas da Luta antimanicomial vêm, gradativamente, reintegrando a loucura aos espaços urbanos. Tal luta, mais do que reformular os serviços de saúde mental, ousa discutir e lutar pela 
reinvenção de espaços na sociedade que incluam o diferente - e ninguém mais que o "louco" para denunciar e impor a diferença (LIMA;YASSUI, 2014). A discussão atravessa, forçosamente, o conceito do que é "civilizado", ou seja, tolerar o estranho não é aceitá-lo, desde que "longe do nosso olhar". Ao contrário, ser civilizado implica “[...] suportar a dúvida, a divisão, a falta de certeza, que cede lugar ao Outro e permite a convivência com a diversidade" (KEHL, 2004, p. 102).

Os passos em direção ao pleno processo da Reforma ainda são lentos e graduais, pois envolvem uma complexidade de implicações. A falta de recursos e problemas na gestão do SUS soma-se a uma fantasmática produzida historicamente sobre a figura do louco, gerando uma gama de saberes e poderes, que de forma dominante buscam adestrar e normalizar conforme um modelo de saúde. A luta antimanicomial, em uma perspectiva crítica ao modelo biomédico, propõe uma mudança paradigmática na noção de saúde e doença. Nesse sentido, pauta-se pela participação ativa dos sujeitos nos seus trajetos no campo da saúde mental, questiona cristalizações de maneira a não subordinar o usuário ao conhecimento técnico-científico e a realocar a loucura no laço social. Para tal, é fundamental o cuidado em rede e o uso da cidade como aporte técnico e político na perspectiva antimanicomial.

Há uma estética do cuidado que implica diferentes formas de fazer saúde na contemporaneidade. Entendendo que os saberes são incompletos por si só, barrados, divididos, torna-se necessário organizar e matriciar a rede de cuidado em saúde mental de maneira intersetorial, interdisciplinar e dinâmica (PEREIRA, 2014), possibilitando o conceber e o agir com o cuidado em saúde. A noção de rede implica a dimensão da alteridade (ELIA, 2005). Assim, o trabalho em rede e o uso da cidade exigem pensar a singularidade como um arranjo único, bem como sustentar uma prática comprometida com a ética do sujeito: sujeito singular, histórico e relacional. A busca da ampliação da autonomia envolve o fortalecimento das relações sociais, através de redes afetivas e de cuidado, pautadas na ética de um sujeito de direitos e de desejo.

\section{Acompanhamento Terapêutico: a clínica a céu aberto e os lugares na cidade}

Instituir por lei os princípios da Reforma Psiquiátrica não é suficiente. É preciso criar e fortalecer estratégias que preconizem o cuidado em liberdade, tendo a internação apenas quando os recursos extra-hospitalares se mostrarem insuficientes. O Acompanhamento Terapêutico 
configura-se como um estratégico dispositivo clínico-político alinhado a essa perspectiva, favorecendo tanto o cuidado em rede como auxiliando na desinstitucionalização de sujeitos que passaram por longos períodos de internação. Analisa-se o AT como um modo de escuta e de clínica potencialmente transformadora, voltado aos casos de maior isolamento, desamparo e vulnerabilidades, que interrogam a rede de atenção psicossocial pela precariedade de laços afetivos, materiais e pela não adesão aos tratamentos.

Ao resgatar o sujeito de seu enclausuramento, seja no confinamento do quarto, das instituições de saúde e/ou assistência, o AT permite um espaço de ressignificação, usando o público e o social como dispositivo para essa terapêutica (CABRAL, 2005). A partir do encontro dos saberes psi com o espaço e tempo da cidade, ele configura-se como uma clínica em movimento que ocorre entre lugares (PALOMBINI, 2007). Nessa, as andanças vão de um ponto a outro, percorrendo o limiar entre o público e o privado, o exterior e interior, a casa e o serviço de saúde, o familiar e o estranho.

No que tange ao método do AT, Hermann (2013) ressalta que a construção de uma presença do acompanhante na relação com o acompanhado é fundamental para a instalação do dispositivo de tratamento AT. Tal perspectiva pauta-se na ideia de transição entre dois tempos presentes na direção do tratamento: do primeiro tempo - aquele que remete à construção de uma presença do acompanhante terapêutico, cobrindo uma ausência incondicional anterior - ao segundo tempo, que direciona ao esvaziamento da presença do acompanhante, o apagamento gradual de sua voz e olhar, para que o sujeito se posicione diante do laço social. Dessa maneira, a partir do que se experiencia nos trajetos pela cidade, no encontro com outras pessoas, nos percursos e acontecimentos oriundos dos atendimentos (e que assumem um caráter inédito), o acompanhante contribui para a estabilização do acompanhado na cultura, promovendo pontos de encontro do sujeito psicótico com o laço social (HERMANN, 2013).

Nesse sentido, abre-se a possibilidade de uma escuta pautada na ética da psicanálise. $\mathrm{O}$ acompanhante, ao lado do acompanhado, assume uma postura de secretariar o sujeito, colocandose em segundo plano, para que a singularidade do acompanhado se coloque em evidência. Ele acompanha o sujeito no resgate de sua subjetividade, traçando pela cidade algumas possibilidades de representação tanto de si, quanto de sua história, por meio da fala. O AT possibilita a emergência da palavra através dos caminhos trilhados, além de viabilizar encontros cotidianos no espaço público que tendem a produzir efeitos importantes na vida dos sujeitos com diagnóstico 
de psicose. Ao mesmo tempo em que se sustenta uma posição de proximidade com a loucura, não se ignora a dimensão de tratamento: o encontro com o laço social e a orientação pela concepção de subjetividade (HERMANN., 2013).

Palombini (2007), a partir da leitura de Cabral (2005), ressalta que tais efeitos só são possíveis porque não se trata de uma mera circulação, mas sim de uma dimensão subjetiva do acontecimento; acontecimento que representa o encontro com a alteridade, com a diferença, que se dá no tempo e ambiente concreto da cidade. $\mathrm{O}$ acontecimento remete àquilo que provoca uma ruptura na posição em que o sujeito se encontra enclausurado. Nessa perspectiva, é através do encontro com a diferença que se aposta na ocupação de um novo lugar social para o louco, na produção de deslocamentos e no reposicionamento subjetivo. A utopia que a clínica do AT busca ativar é a da cidade como polis, aberta ao encontro com o diferente e território de negociação e conflitos (PALOMBINI, 2009). Tal horizonte de trabalho produz efeitos no campo da clínica e, também, da política.

A mesma autora faz um paralelo entre o acompanhamento terapêutico e as figuras do flâneur $e$ do trapeiro retratadas por Walter Benjamin, especialmente no que se refere à relação com a cidade (PALOMBINI 2007; 2009). Nesse sentido, o flâneur é aquele que vagueia pelas ruas num ritmo diferente da temporalidade hegemônica, experienciando a dissolução dos limites entre interior e exterior; a estrangeiridade; a temporalidade passado-presente-futuro da cidade; e o andar à deriva. Já o trapeiro, durante o percurso, apanha restos e fragmentos da história e coleta e transforma os rejeitos da cidade para lhes dar novos usos e sentidos. Mas, diferente do flâneur e do trapeiro, o AT não se revela de maneira solitária e só é possível se aliado ao que é referido como exercício da amizade, que se serve das diferenças potencialmente transformadoras das relações e suas formas (PALOMBINI, 2007; 2009)

O AT pode se servir da compreensão de cidade adotada pela PA, em especial dos conceitos de espaço e lugar nos estudos pessoa-ambiente. O processo de urbanização influencia e é influenciado pelo modo de vida das pessoas, ao passo que a concretude das cidades é a projeção das relações sociais (LEFEBVRE, 2001). Portanto, a cidade e suas ruas, bairros, praças e edificações, possui uma atmosfera que lhes é própria e que extrapola o planejamento urbano e a geografia, já que revela identidades e discursos de pessoas que ali habitam e circulam. Logo, são as experiências do acompanhante ao lado do acompanhado que definem o que é espaço e o que é lugar. 
O espaço denota amplidão, movimento e liberdade, e se remete ao aspecto físico, à concretude, às dimensões e delimitações de uma área: o espaço pode conter objetos inanimados, seres vivos, e todo tipo de matéria; e pode ser identificado a partir de uma referência espacial. Portanto o espaço pode ser medido entre dois pontos, dois objetos, criando distâncias e delimitações. Já a constituição de lugar pode demandar pouco ou mais tempo, e, ao contrário da noção de espaço que denota movimento, o lugar é compreendido como pausa, porque implica relação e vínculo (CAVALCANTE; NOBREGA, 2011; TUAN, 1983).

As cidades podem assumir a condição de lugar, e também podem conter infinitos lugares distinguidos por pessoas ou por grupos (HISSA; MELLO, 2008). O lugar é o espaço vivido e sentido, onde se inscrevem histórias. Parte-se do entendimento de que os lugares são constituídos na relação das pessoas com os espaços, por meio dos sentidos e significados a eles atribuídos e que extrapolam suas propriedades objetivas. Portanto, o dispositivo do AT, além de contribuir para que o psicótico experiencie o laço social, promove a constituição de lugares. Ora, se o lugar é produção humana, logo é construção incessante, revela a tensão entre as pausas e os movimentos inerentes à vida urbana.

\section{Considerações Finais: promoção de cuidado na cidade, através do fortalecimento de laços}

A cidade, se entendida como "casa", como lugar onde se habita, possui, para além de sua dimensão concreta, sentidos e significados que constituem subjetividades. Deste modo, extrapolase o conceito geográfico de cidade, para pensá-la como “[...] símbolo complexo e inesgotável da existência humana" (FONSECA, 2003, p. 256). Buscou-se refletir sobre a singularidade de apropriação dos espaços por parte daqueles que tendem a ser colocados à margem, como é o caso dos sujeitos com estruturação psicótica. A diferença dos seus tempos e espaços em relação à norma, que tende a regular as cidades, produz estranhamentos e, de forma mais cruel, enclausuramentos como estratégia preferencial de atenção à saúde mental. As cidades, por sua vez, símbolos da existência humana e da civilidade, com seus arranjos espaciais revelam os contrastes e as tensões. Entretanto, a tentativa de profilaxia do meio urbano, de efeito uniformizador, busca excluir tudo aquilo que difere e questiona a lógica hegemônica. Contrapondo-se a esse apagamento e exclusão das diferenças e singularidades, o AT apresenta-se como dispositivo clínico que preconiza o cuidado em liberdade. 
Quando realizado com sujeitos psicóticos, trabalha na via de secretariar a reconstrução de laços sociais e espaços de circulação. Nessa perspectiva é uma clínica movente, que se dá no espaço de circulação do sujeito, com efeitos sobre os sujeitos e as cidades. Ao recuperar, sublinhar e amarrar sentidos esfacelados e desconexos, na escuta e intervenção clínica do AT com a psicose, produz-se saúde mental, pois se possibilita ampliar a circulação pela cidade e fortalecer laços e redes. A cidade, na medida em que acolhe a diferença dos tempos e espaços da loucura, transforma-se em espaço de solidariedade e ética nas relações humanas.

É no encontro entre as divergências da cidade que a modalidade do AT se sustenta, visando à integração dos sujeitos em situação de vulnerabilidade. Mesmo que a lógica hegemônica contemporânea preze pela pacificação e desocupação dos espaços públicos que denunciam as diferenças, o AT caminha numa lógica de dissenso, provocando rupturas nas cristalizações relacionadas ao louco e impulsionando transformações políticas a partir desta modalidade da clínica da psicose. Portanto, quando se fala em amizade, não se trata de remeter à noção do senso comum de intimidade, intersubjetividade e semelhança, mas do aporte teórico de Foucault e Derrida sobre a política da amizade, que se apoia nas assimetrias capazes de transmutar as formas de se relacionar (PALOMBINI, 2007; 2009).

Para além de um mero caminhar pelas ruas, o dispositivo de AT propicia o processo de co-construção pessoa-cidade, indo ao encontro do entendimento em PA de que a interação com o ambiente físico extrapola a simples ocupação corporal, já que é atravessada pelos significados e apropriações atribuídos aos espaços (BOMFIM, 2010). O que se busca é o fortalecimento do laço social e a ampliação de circulação para aqueles que divergem das normas sociais - e não a adequação a um modelo pré-estabelecido de habitante da cidade. Desta forma, recupera-se a cidade como espaço da diferença e do convívio. Criam-se estratégias de enfrentamento da exclusão, minimização da vulnerabilidade e promoção de saúde mental, ao buscar o cuidado em liberdade pela ampliação dos territórios simbólicos, possibilitando encontros, construções e fortalecimento de redes afetivas e de cuidado. 


\title{
TIES WITH MADNESS: THE CITY AS A SPACE OF PROMOTING MENTAL HEALTH
}

\begin{abstract}
This essay discusses the relation between city and madness. It seeks to analyze public space with its norms and deviations and also reflects about mental health care. Argues the Therapeutic Accompaniment in its anti-asylum perspective and discusses the strengthening of mental health care without seclusion. Dialogues with the perspective of environmental psychology and psychoanalysis, in order to consider the complex web involving madness, city, social bond and mental health.
\end{abstract}

Keywords: Therapeutic Accompaniment; Psychoanalysis; Environmental psychology.

\section{LAZOS CON LA LOCURA: LA CIUDAD COMO ESPACIO DE PROMOCIÓN DE SALUD MENTAL}

\section{Resumen}

Este ensayo aborda la relación de la ciudad con la locura. Busca analizar el espacio público con sus normas y desvíos y reflexionar sobre el cuidado en salud mental. Aborda el dispositivo del Acompañamiento Terapéutico en su perspectiva antimanicomial y de fortalecimiento del cuidado en libertad. Dialoga con la perspectiva de la psicología ambiental y del psicoanálisis para reflexionar sobre esa compleja trama entre locura, ciudad, lazo social y salud mental.

Palabras-clave: Acompañamiento Terapéutico; Psicoanálisis; Psicología ambiental.

\section{REFERENCIAS}

AMARANTE, Paulo. Diversidade, cultura e direitos humanos: bases para a Reforma Psiquiátrica. In: MELO, W.; FERREIRA, P. A. (Org). A Sabedoria que a gente não sabe. Rio de janeiro: Espaço Artaud, 2011. p. 25-34.

BETTS, Jaime. A pulsão escópica na contemporaneidade. Revista da Associação Psicanalítica de Porto Alegre, Porto Alegre, n.32, p. 49-65, jan./jun. 2007.

Desamparo e Vulnerabilidades no Laço Social - A função do psicanalista. Revista da Associação Psicanalítica de Porto Alegre, Porto Alegre, n. 45-46, jul.2013/jun. 2014.

BIRMAN, Joel. A Cidadania Tresloucada. In: BEZERRA JUNIOR, B.; AMARANTE, P. (Org). Psiquiatria sem Hospício: contribuições ao estudo da reforma psiquiátrica. Rio de Janeiro: Relume-Dumará, 1992. p. 71-90

BOMFIM, Zulmira Áurea Cruz. Cidade e afetividade: estima e construção dos mapas afetivos de Barcelona e São Paulo. Fortaleza: Edições UFC, 2010.

BRASIL. Lei n ${ }^{\circ} 10.216$, de 6 de Abril de 2001. Dispõe sobre a proteção e os direitos das pessoas portadoras de transtornos mentais e redireciona o modelo assistencial em saúde mental. Diário 
Oficial da União, Brasília, DF, 6 Abr. 2001. Disponível em < http://www.planalto.gov.br/ccivil_03/leis/leis_2001/110216.htm>. Acesso em: 25 out, 2017.

CABRAL, Karol Veiga. Acompanhamento Terapêutico como dispositivo da Reforma Psiquiátrica: considerações sobre o Setting. 2005. 122 f. Dissertação (Programa de PósGraduação em Psicologia Social e Institucional) - Universidade Federal do Rio Grande do Sul, Porto Alegre, 2005.

CALLIGARIS, Contardo. Introdução a uma clínica diferencial das psicoses. Porto Alegre: Artes Médicas, 1989.

CAVALCANTE, S.; NOBREGA, L.M.A. Espaço e Lugar. In: CAVALCANTE, S; ELALI, GA. (Org). Temas Básicos em Psicologia Ambiental. Petrópolis: Vozes, 2011. p. 182-190.

ELIA, Luciano. A Rede da Atenção na Saúde Mental - articulações entre CAPS e ambulatórios. In: BRASIL. Ministério da Saúde (MS). Secretaria de Atenção à Saúde. Departamento de Ações Programáticas Estratégicas. Caminhos para uma política de saúde mental infanto-juvenil. Brasília: Editora do Ministério da Saúde, 2005. p. 49-63.

FONSECA, Tania Mara Gali. A cidade Subjetiva. In: FONSECA, T.M.G.; KIRST, P.G. (Org). Cartografias e Devires: a construção do presente. Porto Alegre: UFRGS Editora, 2003. p. 253257.

FOUCAULT, Michel. História da Loucura: na idade clássica. 9. ed. São Paulo: Perspectiva, 2010.

A casa dos Loucos. In: . Microfísica do poder. Rio de Janeiro: Edições Graal, 1979. p. 113-128.

FREUD, Sigmund. O mal-estar na civilização. In: Obras Completas: O Mal-estar na civilização, novas conferências introdutórias à psicanálise e outros textos (1930-1936). São Paulo: Companhia das Letras, 2010. p. 13-123.

GÜNTHER, H.; ROZESTRATEN, R.J.A. Psicologia Ambiental: algumas considerações sobre sua área de pesquisa e ensino. Textos de Psicologia Ambiental, v. 10, p.1-7, 2005.

HERMANN, Maurício Castejon (Org). Acompanhamento terapêutico. São Paulo: Zagodoni, 2013.

HISSA, C.E.V.; MELLO, A.F. O lugar e a cidade: conceitos do mundo contemporâneo. In: HISSA, C.E.V. (Org). Saberes ambientais: desafios para o conhecimento disciplinar. Belo Horizonte: Editora UFMG, 2008. p. 293-308.

KEHL, Maria Rita. O tempo e o cão: a atualidade das depressões. São Paulo: Boitempo, 2009. . Civilização partida. In: NOVAES, Adauto. (Org). Civilização e barbárie. São Paulo: Companhia das Letras, 2004. p. 101-124 
JULIEN, Philippe. As psicoses: um estudo sobre a paranóia comum. Rio de janeiro: Companhia de Freud, 1999.

LACAN, Jacques. Escritos, Rio de Janeiro: Zahar, 1998.

O seminário, livro XVII: o avesso da psicanálise. Rio de Janeiro: Jorge Zahar, 1992 LEFEBVRE, Henri. O direito à cidade. São Paulo: Centauro; 2001.

LIMA, E.M.F.A.; YASUI, S. Territórios e sentidos: espaço, cultura, subjetividade e cuidado na atenção psicossocial. Saúde em Debate, p. 593-606, 2014.

MADEIRA, Manoel. Corpo e violência estrutural das psicoses: o suicídio do outro em Louis Althusser. Revista da Associação Psicanalítica de Porto Alegre, Porto Alegre, n. 45-46, jul.2013/jun.2014

PALOMBINI, Analice de Lima. Acompanhamento terapêutico na rede pública: a clínica em movimento. Porto Alegre: Editora da UFRGS, 2004.

- Vertigens de uma psicanálise a céu aberto: a cidade: contribuições do acompanhamento terapêutico à clínica na reforma psiquiátrica. 2007. 248 f. Tese (Programa de Pós Graduação em Saúde Coletiva) - Universidade do Estado do Rio de Janeiro, Rio de Janeiro, 2007.

. Utópicas cidades de nossas andanças: flânerie e amizade no acompanhamento

terapêutico. Fractal: Revista de Psicologia, v. 21, n. 2, p. 295-318, 2009.

PEREIRA, Robson Freitas. Imagens, apesar da catástrofe. Revista da Associação Psicanalítica de Porto Alegre, Porto Alegre, n. 45-46, jul.2013/jun.2014.

PINHEIRO, José Queiroz. Psicologia Ambiental brasileira no início do século XXI: sustentável? In: YAMAMOTO, O.H.; GOUVEIA, V.V. (Orgs). Construindo a psicologia brasileira: desafios da ciência e prática psicológica. São Paulo: Casa do Psicólogo, 2003. p. 280-313.

ROTELLI, Franco. A instituição inventada. In: NICÁCIO, F. (Org). Desinstitucionalização. São Paulo: Hucitec, 1990. p. 89-99.

ROUDINESCO, Elisabeth. Por que a psicanálise? Rio de Janeiro: Zahar, 2000.

SENNET, Richard. Carne e pedra: o corpo e a cidade na civilização ocidental. Rio de Janeiro: BestBolso, 2008.

QUINET, Antonio. Um olhar a mais: ver e ser visto na psicanálise. Rio de Janeiro: Zahar, 2002.

TUAN, Yi-Fu. Espaço e lugar: a perspectiva da experiência. São Paulo: DIFEL, 1983. 
Data de recebimento: 03/04/2018

Data de aceite: 03/07/2019

\section{Sobre as autoras:}

Luísa Susin dos Santos é Psicóloga. Residente em Saúde Mental Coletiva da Universidade Federal do Rio Grande do Sul. Membro do Laboratório de Psicanálise, Processos Criativos e Interações Políticas/UFSC. Endereço Eletrônico: luisasusin@ gmail.com

Camila Klein é Mestre em Psicologia pela Universidade Federal de Santa Catarina - UFSC Brasil. Endereço Eletrônico: kleincamila.ck@gmail.com

Ana Lucia Mandelli de Marsillac é Psicanalista, Professora Dra. do PPG Psicologia UFSC e da Residência Integrada Multiprofissional em Saúde HU/UFSC. Coordenadora do Laboratório de Psicanálise, Processos Criativos e Interações Políticas/UFSC. Membro da APPOA. Endereço Eletrônico: 2206ana@gmail.com

Ariane Kuhnen é Professora Titular no Departamento de Psicologia da Universidade Federal de Santa Catarina e Coordenadora do Laboratório de Psicologia Ambiental - LAPAM/UFSC. Endereço Eletrônico: ariane.kuhnen@ufsc.br

\footnotetext{
${ }^{1}$ Essas duas perspectivas afastam-se sob alguns aspectos, como na própria concepção de sujeito, mas aproximam-se no entendimento da relevância de reflexão sobre as relações com o contexto, com o espaço, na constituição da subjetividade.

${ }^{2}$ Para a teoria psicanalítica desdobrada por Jacques Lacan (1998), o conceito de Outro refere-se a uma abstração do social, dos valores e ideais da sociedade.
} 